\title{
A reintegração de crianças-soldado nas operações de paz da ONU
}

\section{The reintegration of child soldiers in UN peace operations}

\section{INTRODUÇÃO}

O programa de Desarmamento, Desmobilização e Reintegração (DDR) é considerado pela ONU parte integrante dos processos de construção e manutenção da paz. ${ }^{1}$ Em muitos países, o programa está previsto nos próprios mandatos das Operações de Manutenção da Paz (OMP) e foi desenvolvido como um modo de conferir identidade civil aos ex-combatentes associados às partes beligerantes de um conflito, a fim de evitar que voltem a participar das hostilidades (DKPO 2015).

O programa possui três fases principais: o desarmamento - que consiste na coleta, documentação, controle e descarte de armas pequenas, munição, explosivos e armas leves; desmobilização - referente à libertação formal e controlada de combatentes de forças armadas e grupos armados e que inclui uma fase de reinserção que, por sua vez, ocorre quando ex-combatentes adquirem estatuto civil e ganham emprego e renda sustentável; e a reintegração - processo econômico e social a longo prazo em que o combatente é finalmente reintegrado à sociedade civil. Todas essas etapas constituem um processo político a curto, médio e longo prazo que conta com a participação dos ex-combatentes, governos, partes beligerantes, população local e organismos da ONU (UNDDR 2015).

A princípio, o programa destinava-se somente aos combatentes adultos, porém passou a abranger as crianças-soldado. ${ }^{2}$ Isso ocorre porque, sobretudo a partir da década de 1990, houve um maior interesse, tanto dos organismos internacionais quanto da comunidade acadêmica, em discutir

Giovanna Ayres Arantes Paiva - Doutoranda em Relações Internacionais pelo Programa de Pós-Graduação em Relações Internacionais San Tiago Dantas (UNESP, UNICAMP, PUC-SP). E-mail: giovanna.aap@gmail.com 
o papel desempenhado pelas crianças-soldado nos conflitos armados e entender que o trabalho de recuperação dos ex-combatentes também envolvia as crianças que, muitas vezes, desempenham funções significativas nos conflitos armados. O DDR, então, emerge como uma ferramenta útil para desarmar, desmobilizar e reintegrar as crianças que participaram de um conflito. Entretanto, a fase específica de reintegração da criança em sua sociedade é complexa e demanda uma análise mais aprofundada. Assim como ocorre com ex-combatentes adultos, desarmar e desmobilizar as crianças não garante um retorno automático à vida civil. A reintegração consiste em completar a transição das crianças-soldado à sociedade civil, levando em consideração as opções que as esperam nas suas respectivas realidades.

Mesmo com a Convenção dos Direitos da Criança, de 1989, que ressalta o melhor interesse da criança (child's best interests), ou seja, confere certa autonomia à criança a fim de que ela expresse seus anseios e necessidades, é questionável até que ponto o modelo de reintegração promovido pelo DDR e pelas OMP garantem o interesse da criança. Apesar de existir um empenho em incluir a criança-soldado no processo de DDR - como pode ser observado no documento Os Padrões Integrados de DDR (The Integrated DDR Standards - mais conhecido pela sigla em inglês: IDDRS), de 2006, que consiste em um guia inédito de normas para o DDR - não se vê um esforço significativo, a fim de envolver as necessidades da criança nos acordos de paz, nos processos de paz ou nos mandatos das OMP, nos países que passaram pelo DDR.

Dessa forma, o que norteia essa pesquisa é a tensão existente entre promover o melhor interesse da criança - ou seja, sua participação ativa no processo de reintegração - e a imposição de um modelo de reintegração que não é preparado para ouvir a criança. A bibliografia relativa à sociologia da infância reflete essa questão, pois, por um lado, a enxerga como um ser passivo e vitimizado - portanto, sem espaço para ser ouvida - por outro lado, a enxerga como um ator social, agente de suas próprias transformações. Dessa forma, o problema que propomos aqui é: em que medida o princípio de melhor interesse da criança influenciou o modelo de reintegração de crianças-soldado nos mandatos das OMP da ONU? Nossa hipótese é que essa influência foi limitada, pois houve uma ênfase a tal princípio nos documentos que versam sobre o DDR, entretanto não houve uma inclusão das crianças nos processos de construção da paz, nos acordos de paz ou nos mandatos das OMP, fatores essenciais para garantir a reintegração da criança-soldado na sociedade.

Apesar de a temática abordada ser fundamental, visto que permite pensar em estratégias de reintegração da criança-soldado, ela não tem recebido a devida atenção nos debates acadêmicos. Por isso, propomos contribuir para essa área e, potencialmente, a partir de uma análise aprofundada 
dos problemas envolvidos nessa reintegração, sugerir contribuições para o aprimoramento das práticas de DDR.

Consideramos que o presente artigo pode contribuir para fortalecer os estudos sobre crianças-soldado no campo de Relações Internacionais. A temática abordada nessa pesquisa insere-se nos debates sobre Segurança Internacional, visto que o DDR é concebido como parte de um processo de manutenção da paz e que as crianças desempenham funções relevantes durante e após os conflitos armados. Apesar de existirem vários documentos internacionais que abordam a questão da criança em conflitos arma$\operatorname{dos}^{3}$ e de haver uma bibliografia que trata das crianças-soldado (Honwana 2006; Singer 2001; Tabak 2014; Wessels 2006), o debate acerca de sua reintegração durante o processo de manutenção da paz merece ser analisado com mais profundidade, dado que sua presença na agenda de Relações Internacionais é relativamente nova. ${ }^{4}$ Nessa pesquisa, os estudos sobre a sociologia da infância (Ariès 1981; Bühler-Niederberger e Van Krieken 2009; Hart 1992; Sarmento 2005) serão ferramentas complementares que nos ajudarão a entender os modos pelos quais os diversos documentos internacionais enxergam a criança: por um lado, há a interpretação da criança como ser passivo e vitimizado e, por outro, há a interpretação da criança como um ator social. A base dessas duas linhas interpretativas encontra-se nos estudos sobre sociologia da infância, por isso a pesquisa aqui proposta justifica-se também pela necessidade de trazer os estudos sobre a infância para enriquecer os debates acerca das crianças-soldado no processo de manutenção da paz nas Relações Internacionais. Visto que o conflito armado é um fenômeno interdisciplinar, assim como os estudos sobre a infância, a abordagem deste trabalho não podia deixar de sê-lo, pois possibilita uma análise mais aprofundada do complexo fenômeno da reintegração de crianças-soldado na vida civil e sua compreensão nas Relações Internacionais.

Ademais, dado que o emprego de crianças-soldado é um problema que afeta diversas regiões do mundo, inclusive países da América Latina (como Colômbia e Haiti), e que, como o Brasil tem se engajado em Operações de $\mathrm{Paz}$ da ONU, é importante enriquecermos os debates sobre esse tema para estarmos mais preparados para lidar com os dilemas que, inevitavelmente, fazem parte dessas operações.

\section{O PROGRAMA DE DDR E O MELHOR INTERESSE DA CRIANÇA}

Muitos estudos sobre as crianças-soldado são interdisciplinares, sendo que alguns autores recorrem a áreas como antropologia (Cabral 2005; Honwana 2006) e sociologia (Singer 2001; Wessels 2006) para um entendimento mais aprofundado de diversas questões que perpassam a utilização 
de crianças-soldado em conflitos armados como os motivos pelos quais elas se juntam às partes beligerantes, suas funções durante os conflitos armados, quais são suas necessidades no pós-conflito, quais os mecanismos que a ONU utiliza para combater o emprego de crianças-soldado e quais as funções que a Unicef e o Conselho de Segurança desempenham nessa conjuntura. No Brasil, uma importante bibliografia foi produzida por Jana Tabak em sua dissertação de mestrado (2009), acerca do processo de DDR, e em sua tese de doutorado (2014), sobre a construção de um conceito de infância nas Relações Internacionais. Todas essas reflexões oferecem mais elementos que são úteis ao entendimento do processo de reintegração da criança na sociedade e da participação da mesma na manutenção da paz.

Dessa forma, a revisão bibliográfica que será apresentada busca refletir as diversas faces que a discussão sobre as crianças em conflitos armados provocam, com foco em um debate muitas vezes ignorado: a reintegração da criança-soldado. A fim de tornar as abordagens desse tema mais claras, a apresentação da revisão bibliográfica será dividida em três partes.

Primeiramente, será mostrada uma perspectiva mais tradicional da criança, que a retrata como um ser passivo e vitimizado, desenvolvida pelos estudos de sociologia da infância. Tal perspectiva pode ser verificada em documentos da ONU que versam sobre a criança.

Posteriormente, será retratada uma nova perspectiva sobre os estudos da infância, também em bases sociológicas, que enxerga a criança como um ator social. A Convenção dos Direitos da Criança (CDC) reflete essa abordagem ao estabelecer maior participação da criança na sociedade e garantir seu melhor interesse.

Por fim, será feita uma revisão do processo de DDR, ressaltando tanto sua forma mais tradicional quanto sua forma multidimensional, que acompanhou mudanças no próprio modelo das operações de paz, estabelecido mais recentemente. Dessa maneira, será possível verificar o modo pelo qual essas duas perspectivas sociológicas supracitadas refletem-se no DDR de crianças-soldado e quais os traços gerais que o DDR passa a assumir.

A primeira perspectiva retrata a criança como um ser imaturo, passivo, dependente, vitimizado, subordinado e que não participa ativamente da sociedade, pois não tem maturidade para produzir suas próprias opiniões e desejos, ou seja, somente absorve o mundo e molda-se conforme o que é determinado por decisões de adultos. A criança seria, pois, caracterizada pela ausência das características do adulto, como o falar articulado, a maturidade, o desenvolvimento físico e intelectual, o trabalho e o voto, configurando uma incompletude social, física e psicológica (Ariès 1981; Sarmento 2005).

A Declaração dos Direitos da Criança, de 1959, demonstra isso ao considerar que " $[\ldots .$.$] a criança, por motivo da sua falta de maturidade física$ 
e intelectual, tem necessidade de uma proteção e cuidados especiais, nomeadamente de proteção jurídica adequada, tanto antes como depois do nascimento" (ONU 1959, Preâmbulo).

Essa interpretação influencia outros documentos sobre a criança que ressaltam a fragilidade e a falta de discernimento da mesma, como pode ser verificado no Pacto Internacional sobre os Direitos Civis e Políticos e o Pacto Internacional sobre Direitos Econômicos, Sociais e Culturais, ambos de 1966. O primeiro garantia que "[ $[\ldots]$ qualquer criança $[\ldots]$ tem direito às medidas de proteção que exija a sua condição de menor" (ONU 1966a, art. 24), e o segundo assegura que "Os Estados devem também estabelecer limites de idade, sob os quais fique proibido e punido por lei o emprego assalariado da mão de obra infantil" (ONU, 1966b, art. 10). A Convenção 138 da Organização Internacional do Trabalho (OIT), de 1973, também reforçou essa ideia, visando instituir um instrumento geral sobre a matéria a fim de abolir totalmente o trabalho infantil (OIT 1973).

A Declaração sobre Proteção de Mulheres e Crianças em Situação de Emergência ou de Conflito Armado, de 1974 (ONU 1974), e os Protocolos Adicionais I e II da Convenção de Genebra, assinados em 1977, proibiam a participação de menores de 15 anos nas hostilidades e dedicavam especial atenção à proteção das crianças no artigo 77 do protocolo adicional I (ONU 1977), principalmente em épocas de guerra. ${ }^{5}$

Portanto, essa concepção legitimou uma série de medidas com o fim de separar a criança do mundo adulto e garantir sua proteção especial na sociedade. Todavia, a proteção especial destinada à criança também levou à falta de espaço para ela expressar sua voz e suas necessidades na sociedade.

Nos estudos sobre a criança-soldado, Peter Singer (2001) ressalta que as sociedades em que as crianças estão inseridas as obrigam a tomar parte nos conflitos, deixando-as sem escolha e sem oportunidade de mudarem o meio em que vivem. O autor argumenta que muitas crianças são conduzidas ao conflito por pressões além de seu controle, geralmente de natureza econômica. Tais condições estruturais obrigariam as crianças a participar de organizações armadas.

O Relatório Machel - um dos principais estudos acerca das crianças e conflitos armados, produzido pela moçambicana Graça Machel, e publicado no âmbito da ONU - destaca que as escolhas da criança não são verdadeiramente escolhas livres, pois a ação de juntar-se a uma das partes beligerante não é voluntária, mas sim influenciada por uma junção de fatores como pressões culturais, econômicas ou políticas (Machel 1996).

Considerar apenas a estrutura que constrange a criança e sua passividade frente a esse ambiente, apesar de ter garantido legislações mais rígidas quanto à proteção da criança, pode estigmatizá-la e excluí-la das 
atividades sociais. Com efeito, esses documentos geram uma "relação de dependência [...] que reforça a vulnerabilidade estrutural das crianças" (Sarmento 2005).

Ademais, as medidas de proteção das crianças, ressaltadas nos documentos citados, não conseguem aplicar padrões universais do que é a criança e abranger com efetividade todas as situações pelas quais ela passa, principalmente em conflitos armados. O próprio conceito de criança é problemático no sentido em que categoriza por critério de idade processos que, muitas vezes, são culturais, psicológicos e sociais. Nessa pesquisa, utilizamos o conceito de criança da Unicef, estipulado na Convenção sobre os Direitos da Criança, de 1989: "criança é todo o ser humano menor de 18 anos, salvo se, nos termos da lei que lhe for aplicável, atingir a maioridade mais cedo" (Unicef 1989, art. 1). Essa definição estipula um padrão de 18 anos, mas dá margem para lembrar que cada país tem sua própria legislação e direito de definir o que se entende por criança. Entretanto, este mesmo documento estabelece que "Os Estados Partes devem tomar todas as medidas possíveis na prática para garantir que nenhuma criança com menos de 15 anos participe diretamente nas hostilidades" (art. 38) e que "No caso de incorporação de pessoas de idade superior a 15 anos e inferior a 18 anos, os Estados Partes devem incorporar prioritariamente os mais velhos" (art. 38). Já no Protocolo Facultativo à Convenção sobre os Direitos da Criança relativo ao envolvimento de crianças em conflitos armados, de 2000, recomenda-se aos Estados que menores de 18 anos não sejam recrutados à força, tampouco participem das hostilidades (ONU 2000a).

Contrastando com essa perspectiva mais tradicional, emerge a segunda perspectiva que será abordada: a que interpreta a criança como um ator social. O argumento utilizado é que existe uma relativa autonomia cultural da criança em relação ao adulto, ou seja, as crianças "fundam suas culturas a partir dos modos como participam dos mundos naturais e simbólicos com os quais interagem” (Barbosa 2014, 651). A criança, portanto, teria certa autonomia de dar sentido às suas ações como verdadeiros atores sociais.

Essa abordagem da sociologia da infância contribui para a pesquisa aqui proposta no sentido em que considera as crianças como atores sociais plenos. A partir desse ponto de vista, é possível pensar em necessidades próprias da criança, opiniões, culturas e até mesmo participação efetiva na sociedade e em processos de mudança durante e após os conflitos armados (Bühler-Niederberger e Van Krieken 2009; Sarmento 2005).

Segundo Hart (1992), as possibilidades de participação infantil podem ser classificadas em diferentes estágios que vão desde a não participação, passando pelo momento em que finalmente é dada voz à criança, entretanto de forma "aparente e não significativa”, visto que não há a possibilidade 
real da criança formular suas escolhas e decisões, consequentemente tornando-se incapaz de produzir transformações nas questões em que estão inseridas. Seria, pois, mais uma ilusão de participação da criança do que, de fato, um poder transformador. O estágio mais avançado seria aquele em que as ações ocorrem por iniciativa das crianças, com decisões compartilhadas com os adultos.

A Convenção sobre os Direitos da Criança (CDC), em 1989, sinaliza maior possibilidade de autonomia e participação da criança ao determinar que "Todas as ações relativas às crianças, levadas a efeito por instituições públicas ou privadas de bem-estar social, tribunais, autoridades administrativas ou órgãos legislativos, devem considerar, primordialmente, o melhor interesse da criança" (Unicef 1989, art. 3, grifo nosso).

Além disso, o documento cita que:

1 - Os Estados Partes devem assegurar à criança que é capaz de formular seus próprios pontos de vista o direito de expressar suas opiniões livremente sobre todos os assuntos relacionados a ela, e tais opiniões devem ser consideradas, em função da idade e da maturidade da criança. 2 - Com tal propósito, proporcionar-se-á à criança, em particular, a oportunidade de ser ouvida em todo processo judicial ou administrativo que afete a mesma, quer diretamente quer por intermédio de um representante ou órgão apropriado, em conformidade com as regras processuais de legislação nacional (Unicef 1989, art. 12).

Essa abordagem garante maior poder de participação da criança na sociedade, estabelecendo que ela deva participar na determinação de quais são seus interesses, contrastando com a concepção da criança somente como vítima e passiva. O Relatório Machel converge com a CDC ao recomendar que os próprios jovens devem participar dos programas locais de reconstrução e recuperação e que as crianças mais velhas podem até mesmo envolver-se na implementação dos programas para crianças menores. Ademais, Machel ressalta que a participação ativa da criança nesse processo viabilizaria o contato da própria criança com sua comunidade e facilitaria a reintegração a longo prazo. Dessa forma, segundo Machel, deve-se levar em consideração as culturas locais, o desenvolvimento da criança e o entendimento das realidades políticas e sociais. Ainda de acordo com o documento, "Os jovens nunca devem ser vistos como problemas ou como vítimas, mas como contributos-chave nas soluções de planejamento e implementação de longo prazo" (Machel 1996).

Alcinda Honwana (2006) traz uma importante contribuição nesse sentido ao enfatizar o conceito de tactical agency ou agency of the weak, originalmente utilizado por Michel de Certeau. Tal conceito refere-se à situação 
da criança-soldado, na qual sua possibilidade de escolha encontra-se severamente limitada e ela acaba agindo em uma posição de fraqueza, mas sem perder a possibilidade de tomar iniciativa a fim de achar estratégias para lidar com a situação e buscar oportunidades de melhoria ou, ao menos, de sobrevivência. Para os meninos envolvidos em conflitos armados, isso pode significar enganar os seus superiores, mentir, esconder a verdade, realizar roubos não autorizados. Para as meninas envolvidas no conflito - e muitas vezes negligenciadas nos estudos sobre o tema - isso significa desenvolver mais as relações com os soldados que detêm o poder militar, a fim de melhorar a sua própria segurança e, consequentemente, obter acesso a mais conforto material. Entretanto, Honwana não considera que isso seja motivo para responsabilizar legalmente as crianças por seus atos durante os conflitos armados. O argumento da autora é útil, então, para enfatizar que há um discernimento e um poder de ação da criança que podem ser mantidos e levados em consideração durante o processo de reintegração.

Por fim, depois de abordadas as duas perspectivas que enxergam a criança de maneiras distintas, destacamos aqui como o modelo DDR foi influenciado ao longo dos anos por essas concepções. Desde a década de 1990, a ONU tem acompanhado e apoiado processos de DDR em países que se recuperam de períodos de conflito. O primeiro mandato da ONU a apoiar a implementação do programa de DDR foi o Grupo de Observação das Nações Unidas na América Central (ONUCA), em 1990. A partir disso, diversas OMP passaram a incluir o DDR como parte de seu mandato e parte integrante do processo de manutenção e construção da paz, como em Moçambique (1994), Serra Leoa (1999) e República Democrática do Congo (2001) (DKPO, 2010a).

A evolução do DDR acompanhou a evolução das próprias OMP. A princípio, o foco das operações era garantir e monitorar o cessar-fogo. Conforme Bellamy et al. (2004) ressaltam, não havia uma preocupação em trabalhar para uma efetiva solução dos conflitos ou prevenir as causas dos mesmos. As OMP enfocavam mais as negociações entre as partes beligerantes, evitando-se, assim, uma retomada da violência e do conflito. Porém, com a tendência das operações complexas, que procuram lidar com uma grande variedade de questões que perpassam campos como a segurança e os direitos humanos, as OMP passam a ser tidas como multidimensionais, designadas para assegurar a implementação de acordos de paz e apoiar o estabelecimento de uma paz sustentável. O Conselho de Segurança das Nações Unidas (CSNU) autorizou OMP maiores e mais complexas que incluem também civis, polícia e militares e respondem a variados objetivos, como manter a segurança, monitorar os direitos humanos, construir instituições de governança, coordenar eleições no país, reformar o setor de 
segurança e desarmar, desmobilizar e reintegrar ex-combatentes (Bellamy et al. 2004).

É nesse contexto que o DDR ganha maior destaque como uma ferramenta útil de manutenção da paz, visto que as OMP passam a abarcar também a construção e garantia de uma paz duradoura no pós-conflito. Nessa conjuntura, as OMP ganham ainda mais legitimidade de estender seus mandatos e interferirem nas sociedades dos países em que se fazem presentes.

O planejamento das atividades que serão desenvolvidas como forma de reintegrar a criança ganha relevância, pois é a partir dessas atividades que serão traçados os aspectos considerados mais importantes para uma ação efetiva. Porém, isso varia de acordo com as diversas realidades em que o DDR insere-se (Verhey 2001). Alguns priorizam o apoio psicossocial, reconstrução familiar e aceitação da comunidade, todavia nem sempre tal planejamento considera a participação e as necessidades das crianças que serão reintegradas e muitas delas escolhem não procurar os programas de reintegração oficiais. Isso ocorre porque, para entrar no programa, a criança precisa revelar que participou ativamente nas hostilidades. Muitas preferem esconder esse fato e buscar meios próprios de voltar à sociedade civil, sem necessariamente passar pelo DDR e carregar um estigma de ex-criança-soldado. O que faz o DDR para crianças-soldado especial é justamente a tensão entre a imagem do soldado e a imagem da criança - que deve ser reconstruída - o que só pode ser feito com medidas a longo prazo, diferentemente do DDR de adultos, em que medidas a curto prazo são mais utilizadas (Coalition 2008).

Apesar da falta de uma doutrina ou mesmo de normas mínimas no início, o DDR surgiu como uma forma de compreender um elemento integrante dos processos de paz, geralmente introduzidos no início do período pós-conflito e voltados para a construção de confiança entre as partes, que é a reintegração de ex-combatentes. Frente a essas necessidades, o DDR rapidamente passou a ocupar um pilar central nas transições militares-civis e a contar com a participação também do Banco Mundial, de governos doadores e uma série de agências e ONGs (Muggah 2005).

Seguindo a tendência das operações de paz complexas, os programas de DDR foram introduzidos em um espectro mais amplo de ambientes pós-conflito e com objetivos mais abrangentes. Novas metas incluíram: os meios de vida de ex-combatentes e suas comunidades, crianças-soldados, mulheres associadas a grupos armados e combatentes afetados por HIV/AIDS. Esses grupos específicos receberam a denominação de "grupos vulneráveis”, o que já demonstra uma forma de vitimizar a criança (DKPO 2010b). 
Ressaltando a importância das operações de paz complexas, em 2000, o relatório do Painel de Alto Nível sobre Operações de Paz (conhecido também como Relatório Brahimi) enfatizou a necessidade de missões com mandatos mais eficientes para apoiar o processo de paz e a adoção de estratégias de DDR. Estabeleceu-se firmemente uma tendência de que as operações de paz estabelecidas pelo CSNU incluam o DDR em seu mandato, como já aconteceu em países como Burundi, Costa do Marfim, República Democrática do Congo, Haiti, Sudão, apenas para citar alguns casos (ONU 2000b).

Apesar da crescente importância do DDR, ainda não existiam modelos unificados e oficiais do programa. Por isso, agências, departamentos, fundos e programas das Nações Unidas se reuniram em 2004 para elaborar uma série de normas de DDR integradas, ou seja, um conjunto de políticas, diretrizes e procedimentos para os programas de DDR das Nações Unidas apoiados em um contexto de manutenção da paz. Na sequência de discussões de workshops e consultas com profissionais de cada país da ONU, os Estados membros, organizações regionais, organizações não governamentais e o Banco Mundial desenvolveram um projeto de normas para o DDR. Finalmente, em 2006 foi publicado um guia inédito para a aplicação do DDR, o IDDRS (ONU 2006). No que concerne às crianças-soldado, o IDDRS apresentou uma convergência com a Declaração dos Direitos da Criança (CDC), de 1989, ao ressaltar que:

As crianças devem ser autorizadas a expressar as suas opiniões livremente, e essas opiniões devem ser 'devidamente tomadas em consideração de acordo com a idade e maturidade da criança'. As crianças devem ser consultadas em todas as fases do processo de desmobilização e reintegração, e as ações que as afetam deve ser em seus melhores interesses e ter em consideração suas necessidades e preocupações. Em particular, as crianças devem participar na tomada de decisões relativas ao reagrupamento familiar, carreira e oportunidades educacionais (ONU 2006, 4, tradução nossa).

Além do IDDRS, foi publicado em 2010 um documento chamado Segunda Geração de Práticas em Desarmamento, Desmobilização e Reintegração em Operações de Paz: uma contribuição para o debate New Horizon em Desafios e Oportunidades para a Manutenção da Paz da ONU, que estabelece o que seria a Segunda Geração de DDR, ou seja, um conjunto de práticas de DDR que são mais compatíveis com as OMP multidimensionais, pois envolvem as comunidades que são afetadas pelos conflitos de modo geral - incluindo mulheres e crianças - além de como construir confiança, contribuir para um ambiente seguro e ajudar a construir as bases, a longo prazo, para a paz (DKPO 2010b). 
Em 2014, ainda foi publicado o Guia Operacional para os Padrões Integrados de Desarmamento, Desmobilização e Reintegração, que funciona mais como um guia para a implementação do IDDRS. Tais documentos trazem importantes contribuições para a reintegração das crianças-soldado, pois ajudam a nortear a aplicação do modelo de DDR e disponibilizam informações úteis para essa pesquisa no que concerne à elaboração de uma abordagem de DDR específica para crianças (ONU 2014).

Apesar dessas intenções de desenvolver um modelo inclusivo de DDR e de manutenção da paz, a questão das crianças é muitas vezes negligenciada durante as negociações para um acordo de paz e nos mandatos das OMP. De fato, seus direitos garantidos na Convenção dos Direitos da Criança são lembrados, assim como sua especial proteção em situação de conflitos armados. Entretanto, isso não é o mesmo que garantir uma efetiva participação da criança como ator social, como determinado no princípio de melhor interesse da criança. Vale lembrar ainda que a ênfase na proteção da criança é parte de um processo maior de combate ao emprego de crianças-soldado que já vinha sendo esboçado. Desde 1999, a ONU, especialmente por meio de organismos como o Conselho de Segurança e a Unicef, passou a desenvolver campanhas e mecanismos não só de combate ao emprego de crianças-soldado, mas de proteção à criança durante conflitos armados. Inicialmente, em 1998, o emprego de crianças como soldados foi considerado um crime de guerra pelo Estatuto de Roma (ONU 1998). Considerando a criminalização insuficiente, em 1999, o CSNU passou a publicar resoluções inéditas e exclusivas sobre o tema, consolidando-o na agenda de Segurança Internacional. A partir disso, intensificou-se e institucionalizou-se a proteção à criança durante conflitos armados (CSNU 2005).

No ano de 2005, através da Resolução 1612, o Conselho de Segurança reiterou as demais resoluções sobre Criança e Conflitos Armados, como a 1261 (1999) a 1314 (2000), a 1379 (2001), a 1460 (2003) e a 1539 (2004), e reforçou que a proteção das crianças em conflitos armados deve ser um aspecto relevante de qualquer estratégia para resolver conflitos (CSNU 2005). Além disso, foram publicadas resoluções da Assembleia Geral e relatórios da Unicef que conferiam especial atenção às crianças nessas situações (Unicef 2003). Porém, são escassas as menções à maior participação da criança. Na resolução do Conselho de Segurança 1882, de 2009, ressalta-se que efetivos programas de desarmamento, desmobilização e reintegração para crianças, construídos sob o princípio de melhor interesse da criança são cruciais para o bem-estar de todas as crianças, e convoca todos os Estados membros, entidades da ONU, incluindo a Comissão de Construção da Paz, a garantir que a proteção, os direitos, o bem-estar e o empoderamento das 
crianças afetadas por conflitos armados estejam integrados em todo o processo de paz e na reconstrução pós-conflito (CSNU, 2009).

Ainda foi criado o Grupo de Trabalho sobre Crianças e Conflito Armado que monitora o recrutamento de crianças-soldado em países pré-definidos e produz relatórios sobre o tema (Children and Armed Conflict, online). Além de tais medidas, a ONU estabeleceu mecanismos específicos para o acompanhamento da questão como Monitoring and Reporting Mechanism (MRM), a implantação de Planos de Ação e até mesmo sanções com o objetivo de pressionar determinados países a colaborar com os Planos de Ação (CSUN 2005).

No entanto, a ONU não estabelece uma ligação explícita entre a proteção da criança durante os processos de paz e sua participação ativa na sociedade. Quando os processos de manutenção da paz abordam a criança é para reforçar a necessidade de protegê-las, adotando uma ótica que a vitimiza, mas não enfatiza sua efetiva participação como um ator social. No relatório Proteção da Criança na Manutenção da Paz das Nações Unidas: V. I, de 2011 , produzido pelo Departamento de Operações de Paz (DKPO) e pelo Escritório sobre Crianças e Conflito Armado, não há referência a como a criança pode participar do processo de paz (CHILDREN; DKPO 2011).

Portanto, notamos um esforço por incluir o DDR em um escopo mais amplo, característico das operações de paz multidimensionais, que perpassa diversos temas e objetivos como a reintegração do ex-combatente, seja ele homem, mulher ou criança. Percebemos também a inclusão do princípio de melhor interesse da criança no IDDRS. No entanto, não observamos uma convergência entre o que é assegurada na Convenção dos Direitos da Criança e no IDDRS com os processos de manutenção da paz. Nestes, a criança é vista somente como um ser que merece receber uma proteção especial, mas não um ator social capaz de expressar suas necessidades.

\section{CONSIDERAÇÕES FINAIS}

Tendo em vista que esta pesquisa está em fase inicial, a breve revisão bibliográfica aqui apresentada é uma forma de abordar os principais pontos no que se refere ao processo de DDR para crianças-soldado. Podemos perceber que a bibliografia que trata da criança-soldado e de sua reinserção na sociedade perpassa vários aspectos e é interdisciplinar, visto que envolve o processo de paz, mas também reflexões acerca do próprio papel que a sociedade espera que a criança desempenhe. A partir do estudo preliminar até agora desenvolvido, concluímos que o principal ponto que chama atenção nesse tema abordado é a forma pela qual as Operações de Paz ten- 
tam incluir a integração de crianças-soldado em seus mandatos. Ao mesmo tempo em que há uma intenção, expressa em documentos, de tornar as crianças mais ativas em seu processo de reintegração, não notamos uma maior preocupação das missões de paz em acolher as crianças no processo de pós-conflito. Essa contradição é um ponto chave no complexo processo de DDR de crianças-soldado que enseja pesquisas futuras.

\section{REFERÊNCIAS}

Ariès, P. 1981. História Social da Criança e da Família. Rio de Janeiro: LTC Editora.

Barbosa, M. C. S. 2014. Culturas infantis: contribuições e reflexões. Rev. Diálogo Educ., Curitiba, 14 (43), 645-667.

Bellamy, A. J., Griffin, S., Williams, P. 2004. Understanding Peacekeeping. Cambridge: Polity Press.

Bühler-Niederberger, D., Van Krieken, R. 2009. Rethinking the Sociology of Childhood: Competition, Conflict and Cooperation in Contemporary Children's Lives. In: Denis, A., Kalekin-Fishman, D. New Handbook of International Sociology. London: [s/n].

Cabral, I. 2005. Digerindo o passado: rituais de purificação e reintegração social de crianças-soldado no sul de Moçambique. Antropologia Portuguesa 22/23, 133-156. Disponível em: <http://www.uc.pt/en/cia/publica/AP_artigos/AP22.23.06_ Cabral.pdf>. Acesso em: 09 ago. 2015.

Children and Armed Conflict. 2014. Our work. Disponível em: <http://childrenandarmedconflict.un.org/our-work/security-council-working-group/>. Acesso em: 29. Jun. 2014.

Children; DKPO. 2011. Child Protection in United Nations Peacekeeping: Volume I. Disponível em: <http://www.un.org/en/peacekeeping/documents/child_protection\%20_in\%20un_peacekeeping2011.pdf>. Acesso em: 05 ago. 2015.

Coalition To Stop The Use Of Child Soldiers. 2008. Global Report 2008.

CSNU. 2005. Security Council. Resolution 1612. Disponível em: <http://www. un.org/ga/search/view_doc.asp?symbol=S/RES/1612(2005)>. Acesso em: 10 jul. 2015 .

2009. Resolution 1882. Disponível em: <http://www.un.org/en/ga/ search/view_doc.asp?symbol=S/RES/1882(2009)>. Acesso em: 10 jul. 2015. 
Delgado, A. C. C., Müllers, F. 2005. Sociologia da Infância: Pesquisa com Crianças. Educ. Soc., Campinas, 26 (91), 351-360. Disponível em: <cedes.unicamp.br> Acesso em: 24 ago. 2015.

DKPO. 2010a. DDR in peace operations: a retrospective. Disponível em: $<$ http:// www.un.org/en/peacekeeping/documents/DDR_retrospective.pdf > . Acesso em: 06 ago. 2015.

2010b. Second Generation Disarmament, Demobilization and Reintegration Practicies in Peace Operations A Contribution to the New Horizon Discussion on Challenges and Opportunities for UN Peacekeeping. Disponível em: <http://www. un.org/en/peacekeeping/documents/2GDDR_ENG_WITH_COVER.pdf $>$. Acesso em: 09 ago. 2015.

. 2015. Disarmament, Demobilization and Reintegration. Disponível em:

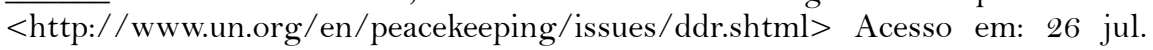
2015.

Hart, R. 1992. Children's Participation from Tokenism to Citizenship. Florence: UNICEF Innocenti Research Centre.

Honwana, A. 2006. Child Soldiers in Africa. Filadélfia: University of Pennsylvania Press.

Machel, G. 1996. Promoção e Proteção dos Direitos das Crianças: Impacto do conflito armado nas crianças. Disponível em: <https://www.unric.org/html/portuguese/ peace/Graca_Machel.htm>. Acesso em: 08 jul. 2015.

Muggah, R. 2005. No Magic Bullet: A Critical Perspective on Disarmament,

Demobilization and Reintegration (DDR) and Weapons Reduction in Post-Conflict Contexts. The Commonwealth Journal of International Affairs, 94 (379), 239-252.

Organização Internacional do Trabalho (OIT). 1973. Convenção 138. Disponível em: <http://www.unicef.org/brazil/pt/resources_10231.htm>. Acesso em: 06 fev. 2015 .

Sarmento, M. J. 2005. Gerações e alteridade: interrogações a partir da sociologia da infância Educ. Soc., Campinas, 26 (91), 361-378. Disponível em: <http://www. scielo.br/pdf/es/v26n91/a03v2691.pdf>. Acesso em: 15 jul. 2015.

Singer, P. W. 2001. Caution: Children at War. Parameters Winter 2001-2002.

Tabak, J. 2009. As Vozes de Ex-Crianças Soldado: Reflexões Críticas sobre o Programa de Desarmamento, Desmobilização e Reintegração das Nações Unidas. 
Dissertação de Mestrado em Relações Internacionais. Programa de Pós-Graduação em Relações Internacionais do Instituto de Relações Internacionais, Pontifícia Universidade Católica do Rio de Janeiro, Rio de Janeiro.

2014. "In the best interest" of whom? Rethinking the Limits of the International Political Order through the (Re)constructions of the World Child and Child-Soldiers. Tese de Doutorado em Relações Internacionais. Programa de Pós-Graduação em Relações Internacionais do Instituto de Relações Internacionais, Pontifícia Universidade Católica do Rio de Janeiro, Rio de Janeiro.

UNDDR. 2015. What is DDR? Disponível em: <http://www.unddr.org/ what-is-ddr/introduction_1.aspx>. Acesso em: 27 jul. 2015.

Unicef. 1989. Convenção sobre os Direitos da Criança. Disponível em: $<$ http://www. unicef.pt/docs/pdf_publicacoes/convencao_direitos_crianca2004.pdf $>$. Acesso em: 30 mar. 2015.

2007 Paris Commitments. Disponível em: <http://www.unicef.org/media/files/ParisCommitments_EN.pdf >. Acesso em: 10 jun. 2015.

2003. Situação Mundial da Infância. House 3 UN Plaza, New York, NY 10017 , USA.

ONU. 1959. Declaração dos Direitos da Criança. Disponível em: <http://www. unicef.org/brazil/pt/resources_10133.htm>Acesso em: 23 jan. 2015.

. 1966a. Pacto Internacional sobre os Direitos Civise Políticos. Art. 24. Disponível

em: $\quad<$ http://www.oas.org/dil/port/1966\%20Pacto\%20Internacional\%20sobre\%20os\%20Direitos\%20Econ\%C3\%B3micos,\%20Sociais\%20e\%20Culturais. pdf>. Acesso em: 06 fev. 2015.

1966b. Pacto Internacional sobre Direitos Econômicos, Sociais e Culturais. Art 10. Disponível em: <http://www.direitoshumanos.usp.br/index.php/Siste ma-Global.-Declara\%C3\%A 7\%C3\%B5es-e-Tratados-Internacionais-de-Prote\% C3\%A 7\%C3\%A30/pacto-internacional-dos-direitos-economicos-sociais-e-culturais-1966.html>. Acesso em: 06 fev. 2015.

1974. Declaração sobre Proteção de Mulheres e Crianças em Situação de Emergência ou de Conflito Armado. Disponível em: <http://direitoshumanos.gddc. pt/3_4/IIIPAG3_4_6.htm>. Acesso em: 06 fev. 2015.

1977. Convenção de Genebra. Protocolo Adicional I. Disponível em: <http://www.gddc.pt/direitos-humanos/textos-internacionais-dh/tidhuniversais/dih-prot-I-conv-genebra-12-08-1949.html>. Acesso em: 03 fev. 2015. 
1998. Rome Statute of the International Criminal Court. Disponível em: $<$ http://untreaty.un.org/cod/icc/statute/english/rome_statute(e).pdf $>$. Acesso em: 10 jan. 2015.

2000a. General Assembly. Panel on United Nations Peace Operations. Disponível em: <http://www.un.org/en/ga/search/view_doc. asp? symbol=A/55/305>. Acesso em: 14 ago. 2015.

. 200ob. Protocolo Facultativo para a Convenção sobre os Direitos da Criança sobre o envolvimento de crianças em conflitos armados. Disponível em: $<$ http://www. unicef.org/brazil/pt/resources_10124.htm>. Acesso em: 08 maio 2015. . 2006. The Integrated DDR Standards (IDDRS).

2014. Operational Guide to the Integrated Disarmament, Demobilization and Reintegration Standards.

Verhey, B. 2001. Child Soldiers: Preventing, Demobilizing and Reintegrating. Africa Region Working Paper Series, 23. Washington: Banco Mundial.

Wessels, M. 2006. Child Soldiers: From Violence to Protection. Massachusetts: Harvard University Press. 


\section{NOTAS}

1. Os termos peacebuilding e peacekeeping são frequentemente usados para se referir aos processos de construção e manutenção da paz, respectivamente. Nessa pesquisa, usaremos os termos em português para facilitar a compreensão dos significados dos termos. De acordo com o Comitê de Política do Secretário-Geral (2007) a construção da paz (peacebuilding) refere-se a uma gama de medidas específicas para reduzir o risco de conflitos por meio do fortalecimento das capacidades nacionais a todos os níveis de gestão de conflitos, e para lançar as bases para a paz e o desenvolvimento sustentável. As estratégias de construção da paz devem ser coerentes e adaptadas às necessidades específicas de cada país e deverão incluir um conjunto de atividades destinadas a alcançar os objetivos referidos. Disponível em: <http:// www.un.org/en/peacebuilding/pbso/pbun.shtml>. A manutenção da paz (peacekeeping), segundo a ONU, é uma ferramenta para apoiar os países a fazer a transição entre conflito e paz. Seus três pilares principais são: consentimento das partes, imparcialidade e não uso da força, exceto em autodefesa do mandato. O DDR está incluído nesse processo. Disponível em: <http://www.un.org/en/peacekeeping/operations/peacekeeping.shtml $>$.

2. O termo criança-soldado ganha destaque como forma de designar não somente as crianças (meninos e meninas) que portam armas, mas também aquelas que desempenham alguma função nas partes beligerantes durante os conflitos como espiãs, cozinheiras, escravas sexuais e mensageiras. A criança-soldado é, pois, a criança que desempenha alguma função junto às partes beligerantes em um conflito armado, de acordo com a definição da Unicef (Unicef 2007).

3. Como a Declaração dos Direitos da Criança (1959), a Convenção dos Direitos das Crianças (1989), o Protocolo facultativo à Convenção sobre os Direitos da Criança relativo ao envolvimento de crianças em conflitos armados (2000).

4. A questão da proteção da criança em conflitos armados foi formalmente consolidada na agenda do Conselho de Segurança da ONU em 1999. A partir disso, o tema ganhou cada vez mais destaque nos documentos internacionais.

5. Também são relevantes os documentos como: Declaração de Genebra sobre os Direitos da Criança (1924); Convenção da Organização Internacional do Trabalho $\mathrm{n}^{\circ} 182$ sobre a Proibição e Ação Imediata para a Eliminação das Piores Formas de Trabalho Infantil (1999); e Protocolo facultativo à Convenção sobre os Direitos da Criança relativo ao envolvimento de crianças em conflitos armados (2000). 


\section{A REINTEGRAÇÃO DE CRIANÇAS-SOLDADO NAS OPERAÇÕES DE PAZ DA ONU}

\section{RESUMO}

O objetivo deste artigo é apresentar uma revisão do processo de Desarmamento, Desmobilização e Reintegração (DDR), previsto nos mandatos das Operações de Manutenção da Paz da ONU, sobretudo a partir de 2000, como a principal forma de efetivar a reintegração de crianças-soldado na sociedade.

Palavras-chave: Crianças-soldado; Nações Unidas; Operações de Paz; Reintegração.

\section{ABSTRACT}

The purpose of this paper is to present a review of the Disarmament, Demobilization and Reintegration (DDR) process provided in the mandates of United Nations Peacekeeping Operations, particularly since 2000, as the main way to accomplish the reintegration of child soldiers in society.

Keywords: Child soldiers; United Nations; Peace Operations; Reintegration. 